\title{
Industrial Ramie growing on reclaimed ion-adsorption Rare Earth Elements mine tailings in Southern China: Defibration and fibers quality
}

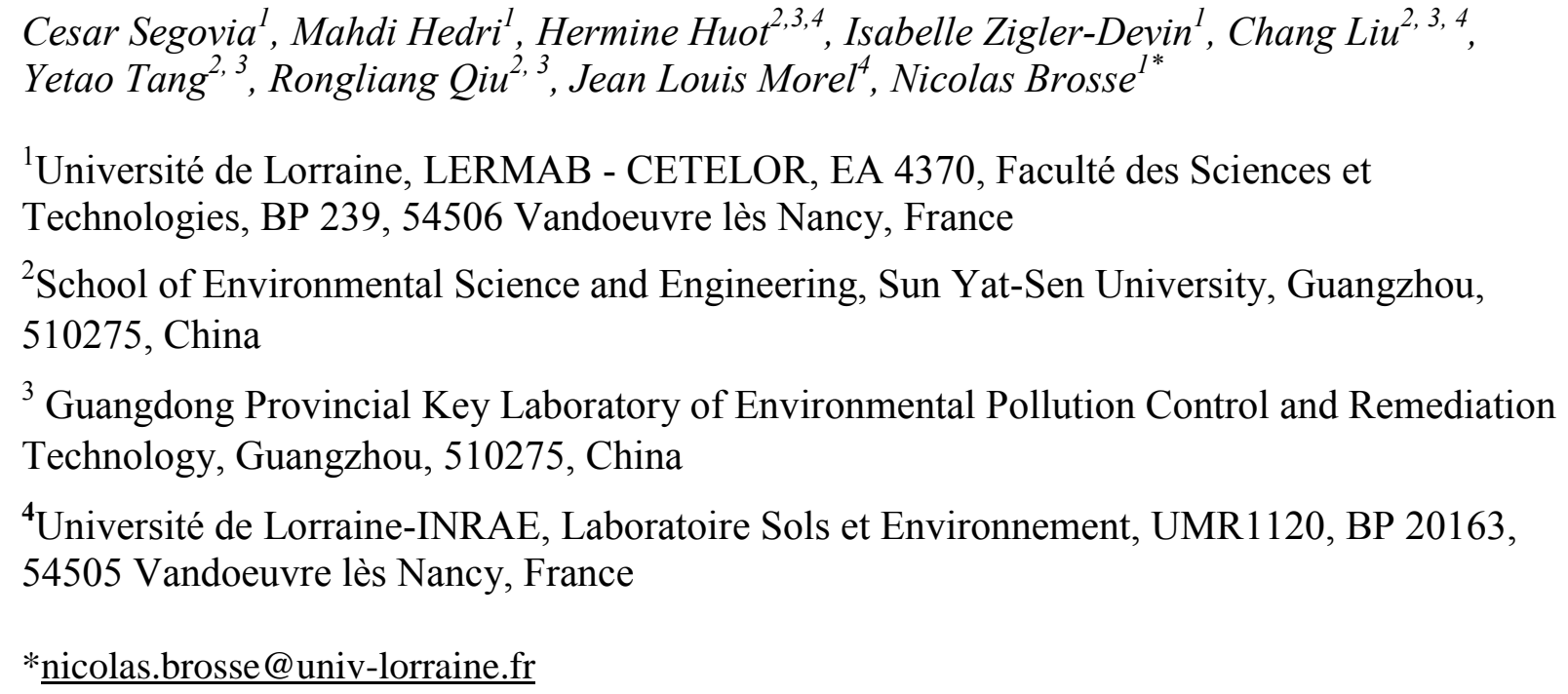

Abstract : Ramie plants (Boehmeria nivea) have been cultivated on ion-adsorption rare earth elements (REEs) mine tailings and showed a low ability to accumulate REEs, especially in the stems $\left(\Sigma \mathrm{REE}=24 \pm 17 \mathrm{mg} \mathrm{kg}^{-1}\right)$ with higher concentration in leaves and roots $(\Sigma \mathrm{REE}=57$ to 66 $\mathrm{mg} \mathrm{kg}^{-1}$ ). Ramie individual fibers were isolated using three degumming processes: a traditional alkali treatment (AT), a steam explosion (SE) treatment after a neutral (SEN) or after a basic (SEB) impregnation. Cellulose-rich (> 80\%) fine fibers with very low amounts of non-cellulosic sugars $(<5 \%)$, low REE concentrations $\left(\Sigma \mathrm{REE} \approx 4-6 \mathrm{mg} \mathrm{kg}^{-1}\right)$ and a high mechanical strength (tensile strength $\approx 260-540 \mathrm{cN} /$ fiber, breaking point $\approx 20-50 \mathrm{cN} /$ fiber) have been produced. However, SE degumming resulted in more degraded fibers with cracks slightly affecting their tensile properties.

Key words : Natural fiber, ramie, degumming, steam explosion, rare earth elements, phytoremediation 
43

44

45

46

47

48

49

50

51

52

53

54

55

56

57 Statement of novelty:

58 Ramie plant produced from a reclaimed rare earth elements rich mine tailing has been 59

60

61

\section{Graphical abstract :}

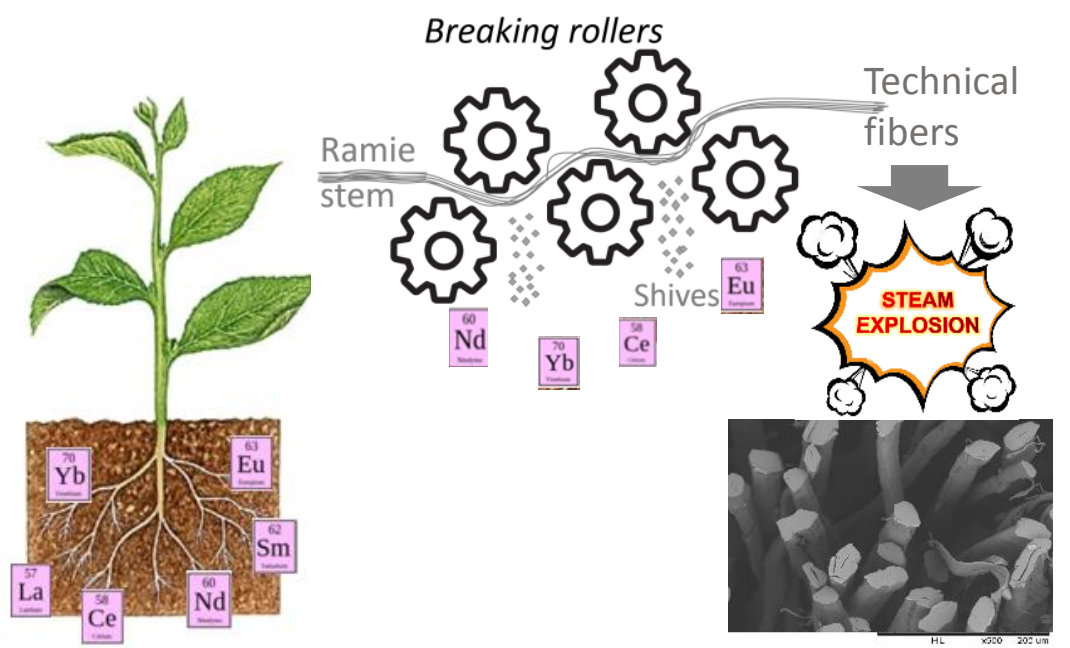

9 evaluated for phytoremediation. The ramie fibers have been extracted using steam explosion a 0 green degumming technology. 
62

63

\section{Introduction}

In recent years, natural bast fibers (such as hemp, flax, jute, ramie) have received an increasing attention due to their economic importance and their renewable and sustainable character [1]. The main advantages of using natural fibers include local availability, low density, biodegradability and carbon sequestration. Bast fibers are composed of elementary fibers which are glued together by a cementing material composed of lignin and polysaccharides [2]. Regardless of the final application concerned (textile or composite), the removal of these non-cellulosic components (lignin, hemicelluloses, pectins) is required prior to downstream processes through a degumming process. In fact, the gummy components negatively affect the spinability of the fibers and, in composite applications, result in poor strength properties of resulting materials. Typically, chemical methods are used for the degumming process using large quantities of sodium hydroxide and other hazardous chemicals [3].

Steam explosion (SE) is an efficient environment-friendly process for bast fibers degumming. In a previous paper, we described the optimization of fine hemp fibers extraction using SE [4]. This method allowed an efficient degumming of the technical hemp fibers and the production of a cotton-like material. Recently, Jiang et al. [5] reported a green degumming process of ramie using steam explosion in comparison with traditional chemical methods. It has been concluded from this study that SE has a great potential for industrial developments for economic and environmental reasons.

Compared to other natural fibers like flax or hemp fibers, ramie (Boehmeria nivea) fibers display outstanding properties such as silk-like appearance, high mechanical strength and high moisture absorption capacity and are among the most popular raw materials for textile application [5-7]. Ramie is grown almost exclusively in China and one of the major limitation 
of the large scale development of ramie industry is the utilization of arable land for the production of non-food biomass. The utilization of plants for the management of polluted land has been described in order to limit the dissemination of pollutants (phytostabilisation). In addition, the cultivation of economic plants, such as fiber or bioenergy crops, can be considered to contribute to the socio-economic development of contaminated areas $[8,9]$. Ramie, characterized by a vigorous root system, a high biomass and a good tolerance to heavy metals, has been shown to be a good candidate for the phytostabilisation of contaminated soils $[10]$.

The demand for rare earth elements (REEs) is increasing worldwide due to their importance in many high-tech products. In Southern China, the ion-adsorption type REE deposits are a strategic resource. For decades, these deposits have been exploited by heap leaching, which consists of the removal of the vegetation, the excavation of the soil layer enriched in REEs and subsequent leaching by ammonium sulfate to recover REEs by ionic exchange. This mining activity has generated important environmental damages, such as large areas of mine tailings subjected to erosion, water contamination by ammonium, sulfate and metals, and landslides. For instance, in Ganzhou city, Jiangxi province, mining activity to recover REEs since 30 years has left more than 300 abandoned mines, 190 million tons of tailings and destroyed more than $150 \mathrm{~km}^{2}$ of forest [11]. Investigation of watersheds impacted by this mining activity in the Dingnan county of Ganzhou city showed the contamination of river waters and sediments and agricultural soils irrigated with contaminated water [12].

Main challenges for the revegetation of these tailings are the strong erosion and unfavorable physical properties (sandy material, poor structure), the low levels of organic matter and nutrients and the relatively high residual REE concentrations [13]. Phytoremediation using amendments and pioneer or tolerant plants have been showed to improve the physico- 
chemical properties of the tailings and to increase biological activity and diversity, suggesting the potential of phytoremediation for the restoration of such mining areas $[14,15]$.

In this context, the utilization of mining areas for growing industrial ramie could be a promising approach not only for the revegetation and phytostabilization of ion-adsorption REE mine tailings but also for biomass production. As a result, the mobilization of non-food phytotechnology ramie fibers for industrial developments could be of particular interest in order to reduce the impacts on the food markets.

In a previous work, we evaluated SE to achieve simultaneously the pretreatment and the decontamination of $\mathrm{Zn}$ and $\mathrm{Mn}$ contaminated willow harvested from an experimental phytoremediation plot for bioethanol production [16]. In the present study, we described the defibration by SE and characterization of ramie fibers harvested on an ion-adsorption REE mining area in Dingnan county (Jiangxi province) in China. REE concentrations in the different compartment of the plant have been examined. The impact of the degumming process used (SE or traditional chemical method) on the ramie fiber quality in terms of chemical and mechanical properties has been examined.

\section{Materials and Methods}

\section{Raw material}

The site of demonstration for the reclamation of ion-adsorption REE mine tailings is located in the Dingnan county of Ganzhou city, Jiangxi province. Details regarding the location, reclamation program and growing conditions are given in the Supplementary Material section S1. Small plants (1 year old, about $35 \mathrm{~cm}$ in height) of the ramie cultivar Zhongzhu No.1 were planted in rows in the amended tailings with a density of 3 to 5 plants per $\mathrm{m}^{2}$ in 2015 . In 2018 , ramie stems (1-2 meters high, $\sim 1 \mathrm{~cm}$ in diameter at the base) were sampled for the analysis of fibers, cut and air-dried for several days. 


\section{Carding and degumming}

Technical fibers were extracted from the ramie stems using a carding machine Bonino, type 250 HL520, with a lining adapted to bast fibers.

Chemical degumming: $10 \mathrm{~g}$ of technical fibers in $200 \mathrm{~mL}$ of $\mathrm{NaOH} 1 \%$ solution in water were heated at $90^{\circ} \mathrm{C}$ with string during $1 \mathrm{~h}$. The treated fibers were filtrated, washed with a dilute acetic acid solution and then water.

SE degumming: Technical fibers were impregnated with a solution of water or of sodium hydroxide ( $2 \mathrm{wt} \%)$. The fibers were macerated during 15 hours at room temperature using a weight ratio water/biomass of $15 / 1$ after what the biomass was filter-pressed $(6.8 \mathrm{~atm}=100$ psi) to remove the excess water. The fibers were transferred into a $2 \mathrm{~L}$ steam gun where about $100 \mathrm{~g}$ (dry basis) of biomass was cooked at temperatures ranging from $170^{\circ} \mathrm{C}$ for 3 minutes by addition of steam in a pressure-resistant reactor. After the cooking period, a pneumatic valve was opened and the vapor phase exited the reactor through a nozzle entraining as well the fibers.

The treated fibers were opened in the carding machine previously described (see below).

Opening the tufts into individual fibers: Card opened the tufts into the stage of individual fibers. This is essential to enable the elimination of impurities and performance of the other operations to be achieved as elimination of dust and removal of short fibers. Mainly for this study to see the effects of the treatment on the opening of the fibers. The schematic of the whole process is given in Fig. 1.

Figure 1.

\section{Chemical analysis}

The experimental details regarding Klason lignin and simple sugars \% determination have been given in previous papers. In short, extractive free fibers were ground and hydrolyzed in 2-steps procedure with sulfuric acid ( $72 \%$ and $4 \%)$. The insoluble residue (Klason lignin) is 
recovered and weighted. The monosaccharide contents were determined from the liquid fraction by HAPE-PAD (ICS-3000 Dionex) equipped with a Dionex CarboPacTM PA-20 (3 x $150 \mathrm{~mm}$ ) analytical column. For experimental details see Simangunsong et al., 2018. The stems, wood and fibers after treatment were analysed for trace elements at the Service d' Analyse des Roches et des Minéraux (CNRS, Vandoeuvre-lès-Nancy, France). Trace element concentrations were analysed using ICP-MS after lithium metaborate attack and acid digestion [17]. Details regarding the soil analysis are given in Supplementary Material section S2.

\section{SEM analysis}

Scanning electron microscopy (SEM) analysis was carried out with Hitachi 3000 microscope. All images were taken at an accelerating voltage of $15 \mathrm{kV}$.

\section{Mechanical properties}

For measuring single fiber properties, Favimat (Textechno Herbert Stein GmbH and Co. KG, Möchengladbach, Germany) was used. The main principle is that both single fiber ends are clamped between two sets of jaws. The displacement is insured by a constant speed motor with interchangeable equipment to vary the rate of elongation. For the tensile tests, the data of the load and elongation were transferred to a computer to be plotted and analyzed. The percentage of elongation and breaking point were determined according to the procedure described in NF EN ISO 50791996 standard method (Textiles fibres - Determination of breaking force and elongation at break of individual fibres). The tensile strength was determined according NF T25-501-2 2015 (Reinforcement fibres - Flax fibres for plastics composites-Part2: Determination of tensile properties of elementary fibres) standard method.

\section{SEM analysis}

Scanning electron microscopy (SEM) analysis was carried out with Hitachi 3000 microscope. 
All images were taken at an accelerating voltage of $15 \mathrm{kV}$. Prior to the analysis, the $\underline{\text { specimens were coated with a thin layer gold/palladium alloy using a sputter coater Quorum }}$

$\underline{\mathrm{SC} 7620}$

\section{Results and discussion}

Technical fibers were extracted in $32 \%$ yield from the ramie stems and separated from the wood using a mechanical decortication process (see section 2). Three degumming methods have been then compared: (1) a traditional alkali treatment, a SE treatment after (2) a neutral or (3) after a basic impregnation (Fig. 1). The experimental conditions used for the degumming steps were based on our previous studies using hemp technical fibers [4].

The compositions of ramie stem, wood, technical fibers and degummed fibers are given in Table 1. Ramie stems displayed relatively high glucans (primarily from cellulose), lignin and xylans contents. After decortication, the woody part retained most of the lignin and xylans, the fibers recovered being cellulose-rich and relatively poor in lignin $(<10 \%)$. Glucomannan has been identified as one of the hemicelluloses of ramie [18]. From the mannose content in the different compartment of the plant listed in Table 1, we can assume that glucomannan is closely associated to the cellulosic fibers whereas xylan is one of the main components of wood. GluA, a marker of pectic components, was recovered in the fiber fraction as well. From Table 1 and in accordance with previous works dealing with ramie fibers degumming, it can be seen that the steam explosion with a basic impregnation is an efficient degumming process, producing cellulose-rich fibers $(\approx 85 \%)$ with very low amounts of non-cellulosic sugars $(<2 \%)$. In our study, the relatively high residual lignin contents obtained are justified by the degumming conditions applied, without bleaching agent.

The composition of the stems and extracted wood, technical fibers and fine fibers in terms of Trace Elements (TE) including Rare Earth Elements (REEs) is given in Table 1. The distribution of trace elements in the soil and organs of ramie grown on amended tailings is 
reported in Supplementary material section S2. In the plants, the average REE concentrations were higher in leaves and roots than in the stems. The major REEs detected in the plant were $\mathrm{La}, \mathrm{Ce}$ and $\mathrm{Nd}$ as well as $\mathrm{Y}$; the other REEs were present in low concentrations $\left(<1 \mathrm{mg} \cdot \mathrm{kg}^{-1}\right)$. The REE bioconcentration factor (leaf concentration/soil concentration) was $0.12 \pm 0.07$ and the REE translocation factor (leaf concentration/root concentration) was $1.3 \pm 0.7$, attesting that ramie has relatively poor ability to accumulate REEs. Main other trace elements in the plant were $\mathrm{Ba}, \mathrm{Sr}, \mathrm{Rb}$ and $\mathrm{Zn}$ (see Supplementary material section $\mathrm{S} 2$ ).

\section{Table 1}

After degumming, it can be observed a strong decrease of REE concentrations in the fine fibers (Table 1), which could be explained by the removal of a part of the pectic polysaccharides which are known to exhibit properties of ions exchange with high affinity for metal ions.

As previously proposed, in the SE process the combination of the steaming step (which provoked the hydrolysis of non-cellulosic components) and the shearing forces (applied during the explosive decompression) increased the extraction ability of $\mathrm{TE}$ in the aqueous stream [16]. As a result, the degumming step appears to be an efficient process for both (1) cleaning TE-enriched phytoremediation-borne ramie fibers and (2) producing superior quality fine fibers with low variability.

Degumming processes produced isolated ramie single fibers having an average diameter of 30 $( \pm 5) \mu \mathrm{m}$ as can be seen in the SEM images given in Fig. 2. In contrast with soda treatment which produced smooth and intact fibers (Fig. 2A), SE degumming resulted in more degraded fibers with cracks and a rough surface (Fig. 2B and C). This can be explained by a degradation under the harsh SE conditions used as previously observed for hemp fibers [4]. The tensile properties of the fine ramie fibers produced were also analyzed in terms of elongation, breaking point and tensile strength. All the results obtained are gathered in Table 
2. The data for cotton fiber was also used as a reference in order to evaluate the ramie fibers produced in this work in textile area. The results obtained compared well with literature: fibers extensional strain at break is lower for ramie $(\approx 4 \%)$ than for cotton fibers $(\approx 9 \%)$ but regarding Breaking Point and Tensile Strength (in $\mathrm{cN}$ ), ramie fibers displayed higher properties [2, 5, 7]. The Elongation and Breaking point of ramie fibers produced by a chemical degumming process $(\approx 4.5 \%$ and $\approx 47 \mathrm{cN}$ respectively) displayed significantly higher values than exploded fibers $(\approx 3.4-3.9 \%$ and $\approx 22-30 \mathrm{cN}$ respectively). These results can be related with the aspect of the fibers given in the Fig. 2, the presence of damaged fibers after SE degumming having probably a negative impact on the tensile properties.

\section{Fig. 2.}

\section{Conclusion}

In terms of phytomanagement, ramie can be cultivated on ion-adsorption REE mine tailings and showed a low ability to accumulate REEs, especially in the stems and in the fibers. From this study we can conclude that SE appeared to be an efficient and green process for both degumming and cleaning phytotechnology ramie fibers. However, the relatively harsh conditions used during the SE degumming step resulted in more degraded fibers slightly affecting their tensile properties. This first field trial on REE ion-adsorption mine tailings showed the feasibility of producing industrial ramie fibers from plants growing on such substrate but further work is needed to optimize the crop management, the degumming step and the utilization of the woody part for a sustainable whole valorization of the ramie plant.

\section{Acknowledgement}


261 LERMAB is supported by the French National Research Agency through the Laboratory of 262 Excellence ARBRE (ANR-12- LABXARBRE-01). This work was supported by the 263 international joint laboratory ECOLAND and by ECOS Sud-CONICYT (France-Chili).

264 


\section{References}

1. Pickering, K.L., Aruan Efendy, M.G., Le, T.M. A review of recent developments in natural fibre composites and their mechanical performance. Compos. Part A. 83, 98112 (2016). doi.org/10.1016/i.compositesa.2015.08.038

2. Bismarck, A., Mishra, S., Lampke, T. Plant Fibers as Reinforcement for Green Composites. In: Mohanty A, Misra M, Drzal L, editors. Natural fibers, Biopolymeres, and biocomposites. Taylor \& Francis. CRC Press. 37-108 (2005).

3. Adamsen, A.P.S., Akin, D.E., Rigsby, L.L. Chemical retting of flax straw under alkaline conditions. Text. Res. J. 9, 789-794 (2002). doi.org/10.1177/004051750207200907

4. Sauvageon, T., Lavoie, J.-M., Segovia, C., Brosse, N. Toward the cottonisation of hemp fibers by steam explosion - Part 1 - Defibration and morphological characterization. Text. Res. J. 88(9), 1047-1055 (2018). doi.org/10.1177/0040517517697644

5. Jiang, W., Song, Y., Liu, S., Ben, H., Zhang, Y., Zhou, C., Han, G., Ragauskas, A.J. A green degumming process of ramie. Ind. Crops Prod. 120, 131-134 (2018). doi.org/10.1016/j.indcrop.2018.04.045

6. Meng, C., Yang, J., Zhang, B., Tu, C. Rapid and energy-saving preparation of ramie fiber in TEMPO-mediated selective oxidation system. Ind. Crops Prod. 126, 143-150 (2018). doi.org/10.1016/j.indcrop.2018.09.030

7. Li, Z., Chen, J., Zhou, J., Zheng, L., Pradel, K.C., Fan, X., Guo, H., Wen, Z., Yeh, M.H., Yu, C., Wang, Z.L. High-efficiency ramie fiber degumming and self-powered degumming waste water treatment using triboelectric nanogenerator. Nano Energy. 22, 548-557 (2016). doi.org/10.1016/j.nanoen.2016.03.002

8. Ding, K., Wu, Q., Wei, H., Yang, W., Séré, G., Wang, S., Echevarria, G., Tang, Y., Tao, J., Morel, J.L., Qiu, R. Ecosystem services provided by heavy metalcontaminated soils in China. J. Soils Sediment. 18, 380-390 (2018). doi.org/10.1007/s11368.016.1547.6

9. Tang, Y.-T., Deng, T.-H.-B., Wu, Q.-H., Wang, S.-Z., Qiu, R.-L., Wei, Z.-B., Guo, X.F., Wu, Q.-T., Lei, M., Chen, T.-B., Echevarria, G., Sterckeman, T., Simonnot, M.O., Morel, J.L. Designing Cropping Systems for Metal-Contaminated Sites: A Review. Pedosphere 22, 470-488 (2012). doi.org/10.1016/S1002-0160(12)60032-0

10. Yang, B., Zhou, M., Shu, W.S., Lan, C.Y., Ye, Z.H., Qiu, R.L., Jie, Y.C., Cui, G.X., Wong, M.H. Constitutional tolerance to heavy metals of a fiber crop, ramie (Boehmeria nivea) and its potential usage. Environ. Pollut. 158, 551-558 (2010). doi:10.1016/i.envpol.2009.08.043

11. Yang, X.J., Lin, A., Li, X.-L., Wu, Y., Zhou, W., Chen, Z. China's ion-adsorption rare earth resources, mining consequences and preservation. Environ. Dev. 8, 131-136 (2013). doi.org/10.1016/j.envdev.2013.03.006 
12. Liu, W.-S., Guo, M.-N., Liu, C., Yuan, M., Chen, X.-T., Huot, H., Zhao, C.-M., Tang, Y.-T., Morel, J.L., Qiu, R.-L. Water, sediment and agricultural soil contamination from an ion-adsorption rare earth mining area. Chemosphere 216, 75-83 (2019). doi.org/10.1016/j.chemosphere.2018.10.109

13. Liu, W.; Liu, C.; Wang, Z., Teng, W., Tang, Y., Qiu, R. Limiting Factors for Restoration of Dumping Sites of Ionic Rare Earth Mine Tailings. Acta Pedol. Sin. 52, 879-887 (2015).

14. Zhou, L., Li, Z., Liu, W., Liu, S., Zhang, L., Zhong, L., Luo, X., Liang, H. Restoration of rare earth mine areas: organic amendments and phytoremediation. Environ. Sci. Pollut. Res. 22, 17151-17160 (2015).

15. Wei, Z., Hao, Z., Li, X., Guan, Z., Cai, Y., Liao, X. The effects of phytoremediation on soil bacterial communities in an abandoned mine site of rare earth elements. Sci. Total Environ. 670, 950-960 (2019). doi.org/10.1016/j.scitotenv.2019.03.118

16. Ziegler-Devin, I., Menana, Z., Chrusciel, L., Chalot, M., Bert, V., Brosse, N. Steam explosion pretreatment of willow grown on phytomanaged soils for bioethanol production. Ind. Crops Prod. 140, 111722 (2019). doi.org/10.1016/.indcrop.2019.111722

17. Carignan, J., Hild, P., Mevelle, G., Morel, J., Yeghicheyan, D. Routine Analyses of Trace Elements in Geological Samples using Flow Injection and Low Pressure OnLine Liquid Chromatography Coupled to ICP-MS: A Study of Geochemical Reference Materials BR, DR-N, UB-N, AN-G and GH. Geostand. Geoanalytical Res. 25, 187198 (2001). doi.org/10.1111/j.1751-908X.2001.tb00595.x

18. Hongshu, Z., Jinggan, Y., Yan, Z. The glucomannan from ramie. Carbohydr. Polym. 47, 83-86 (2002).

19. Mahjoub, W., Harzallah, O. Drean J. Cotton fibre tensile properties. Nova Science Publishers INC. Chapiter 6 115-135 (2017). 
Table 1. Chemical composition of ramie stems, and extracted wood and fibers and distribution of trace elements including Rare earth elements (REEs) in the organs of ramie plants.

\begin{tabular}{|c|c|c|c|c|c|c|c|c|}
\hline & \multicolumn{4}{|c|}{ Chemical composition } & & \multicolumn{3}{|c|}{ Trace elements } \\
\hline & K Lignin $\%^{4}$ & $\mathrm{Glc}^{5}$ & $\left.x y\right|^{6}$ & GalU $^{7}$ & $\operatorname{Man}^{8}$ & $\mathrm{Rb}$ & $\mathrm{Zn}$ & $\Sigma \mathrm{REE}^{9}$ \\
\hline whole stems & $19.7 \pm 1.4$ & $48.9 \pm 1.2$ & $9.3 \pm 0.3$ & $2.7 \pm 0.1$ & $1.5 \pm 0.1$ & $53 \pm 1.9$ & $70 \pm 2.1$ & $17.4 \pm 0.4$ \\
\hline wood & $21.4 \pm 1.2$ & $51.8 \pm 0.9$ & $13.3 \pm 0.7$ & $3.2 \pm 0.2$ & $0.3 \pm 0.0$ & $49 \pm 1.1$ & $60 \pm 1.8$ & $14.9 \pm 0.3$ \\
\hline Raw fibers & $9.7 \pm 0.7$ & $77.4 \pm 1.3$ & $0.4 \pm 0.0$ & $3.1 \pm 0.2$ & $2.0 \pm 0.1$ & $71 \pm 2.2$ & $100 \pm 3.5$ & $6.4 \pm 0.1$ \\
\hline \multicolumn{9}{|l|}{ Fine fibers } \\
\hline $\mathrm{AT}^{1}$ & $7.6 \pm 1.1$ & $82.5 \pm 0.6$ & $0.4 \pm 0.0$ & $2.1 \pm 0.1$ & $2.0 \pm 0.2$ & $1 \pm 0.0$ & $76 \pm 3.2$ & $5.7 \pm 0.1$ \\
\hline SEN $^{2}$ & $7.2 \pm 1.6$ & $81.6 \pm 1.1$ & $0.5 \pm 0.0$ & $2.3 \pm 0.2$ & $2.7 \pm 0.2$ & $3 \pm 0.0$ & $61 \pm 3.0$ & $4.5 \pm 0.1$ \\
\hline $\mathrm{SEB}^{3}$ & $9.9 \pm 0.2$ & $84.1 \pm 0.9$ & $0.3 \pm 0.0$ & $0.6 \pm 0.0$ & $0.7 \pm 0.1$ & $<1$ & $53 \pm 2.7$ & $4.4 \pm 0.1$ \\
\hline
\end{tabular}


345

346

Table 2. Physical properties of ramie fibers extracted with tree different degumming processes, compared with cotton fiber.

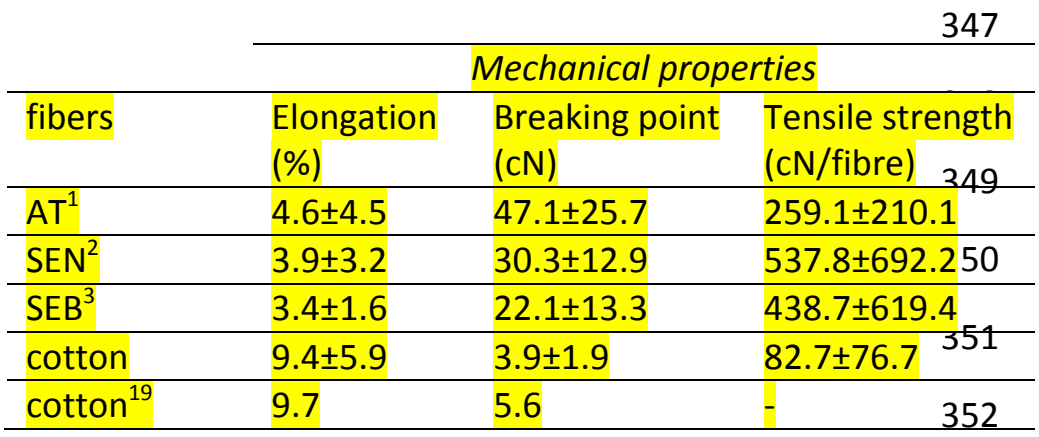

353 alkali treated fibers, ${ }^{2}$ steam exploded fibers after water impregnation, ${ }^{3}$ steam exploded fibers after 354 basic impregnation

356

357

358

359

360

361

362

363

364

365 
Figure 1. Schematic of the process.

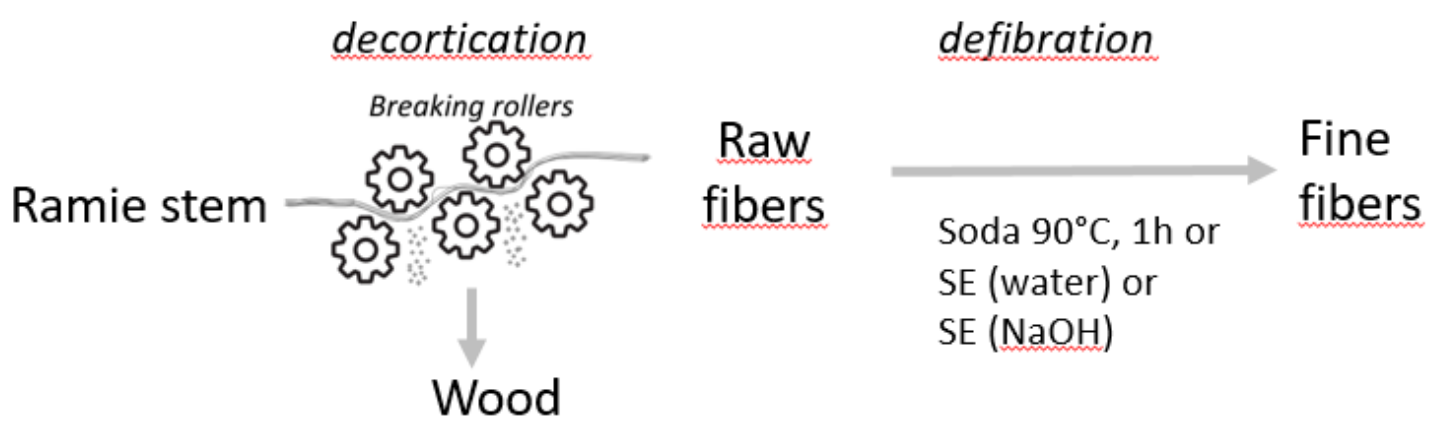

367

368

369 
370

371 Fig. 2. Scanning Electron Microscopy images (x500) of Soda fibers (A), SE treated fibers after water 372 impregnation (B) and SE treated fibers after soda impregnation (C).

373

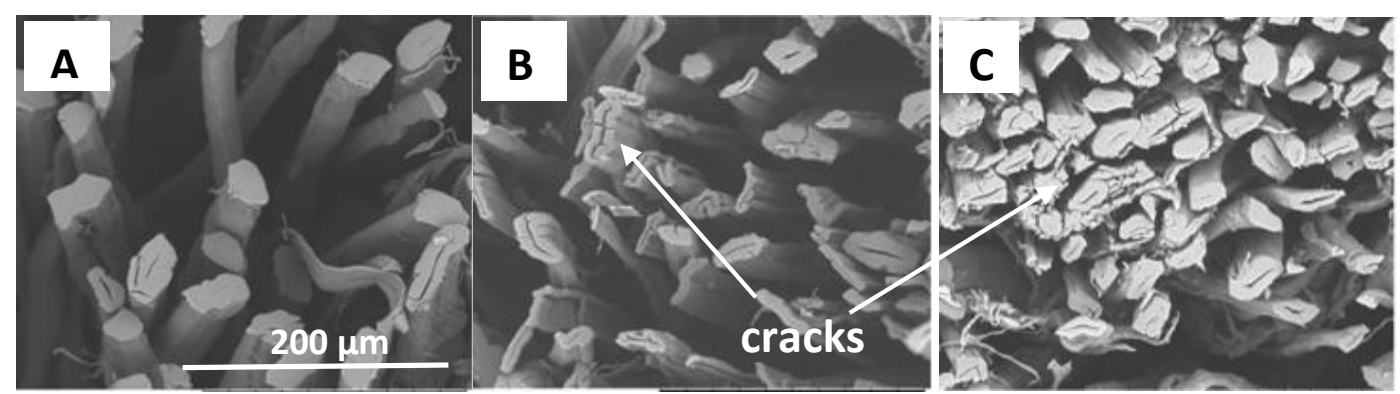

374

375

376

377

378

379

380 


\section{Industrial Ramie growing on reclaimed ion-adsorption Rare Earth Elements mine tailings in Southern China: Defibration and fibers quality}

Cesar Segovia ${ }^{1}$, Mahdi Hedri ${ }^{1}$,Hermine Huot ${ }^{2,3,4}$, Isabelle Zigler-Devin ${ }^{1}$, Chang Liu ${ }^{2,3,4}$, Yetao Tang ${ }^{2,3}$, Rongliang Qiu ${ }^{2,3}$, Jean Louis Morel ${ }^{4}$, Nicolas Brosse ${ }^{1^{*}}$

${ }^{1}$ Université de Lorraine, LERMAB - CETELOR, EA 4370, Faculté des Sciences et Technologies, BP 239, 54506 Vandoeuvre lès Nancy, France

${ }^{2}$ School of Environmental Science and Engineering, Sun Yat-Sen University, Guangzhou, 510275, China

${ }^{3}$ Guangdong Provincial Key Laboratory of Environmental Pollution Control and Remediation Technology, Guangzhou, 510275, China

${ }^{4}$ Université de Lorraine-INRA, Laboratoire Sols et Environnement, UMR1120, BP 20163, 54505 Vandoeuvre lès Nancy, France

\section{S1- Reclamation Program and growing conditions}

The site is located in the Dingnan county of Ganzhou city, Jiangxi province (latitude: $24.989070761774737^{\circ}$, longitude: $\left.115.0527710298679^{\circ}\right)$. The climate is subtropical monsoon humid, with an average annual temperature of $18.8^{\circ} \mathrm{C}$ and average annual rainfall of $1609 \mathrm{~mm}$ (Dingnan County People's Government Network). Natural soils of the area are red soils, formed by the weathering of granitic rocks under subtropical climate. Abandoned since around 10 years, the mine tailings (53 ha) were landscaped in terraces, with steep slopes (> $45^{\circ} \mathrm{C}$ ) subjected to strong erosion in some parts of the site. The vegetation cover was very limited and composed mainly of pioneer species (e.g. Miscanthus sinensis, Pinus massoniana). Since 2015, a reclamation program has been implemented using different plants 
(a)

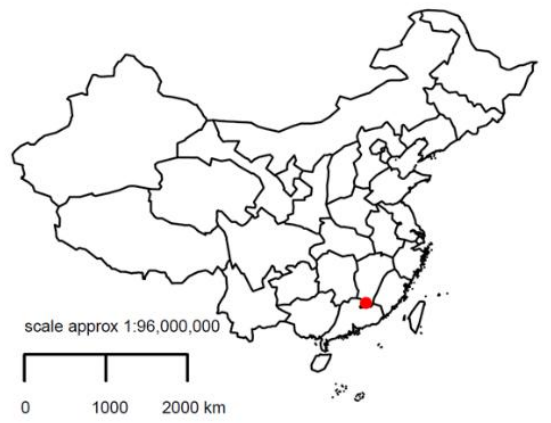

(b)

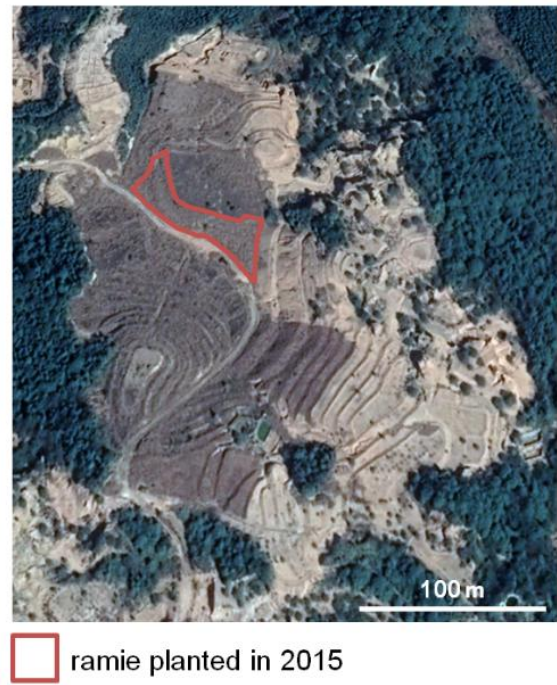

(c)
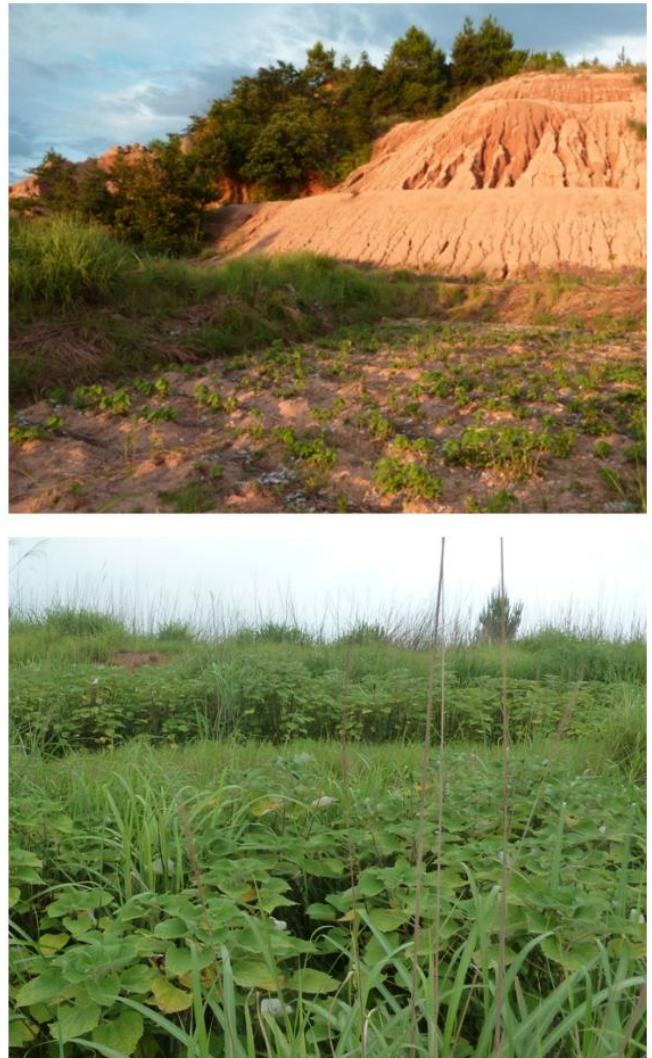

Figure S1- Cultivation of ramie on reclaimed ion-adsorption REE mine tailings

(a) localization of the site in the Dingnan county of Ganzhou city, Jiangxi province, China (b) aerial view of the site taken in 2018 showing the reclamation program with grasses and fiber plants with the delimitation of the plots planted with ramie since 2015 (source: Google Earth) (c) pictures of the ramie cultivated on the mine tailings taken in 2016

Ramie was planted on several terraces $\left(1250 \mathrm{~m}^{2}\right.$ in total) in July 2015. Fresh organic amendment was added with a rate of $50-60 \mathrm{t} \mathrm{ha}^{-1}$ and mixed within the first $12 \mathrm{~cm}$ of the tailings by tillage. One-year plants (about $35 \mathrm{~cm}$ in height) of the ramie cultivar Zhongzhu No.1 were brought from the Institute of Bast Fiber Crops (Chinese Academy of Agricultural Sciences) and planted in rows in the amended tailings with a density of 3-5 plants per $\mathrm{m}^{2}$. In June 2016, the aboveground part of the plants was cut and a granulated NPK fertilizer was 
426

427

428

429

430

431

432

433

434

435

436

437

438

439

440

added with a rate of $450 \mathrm{~kg} \mathrm{ha}^{-1}$. In March 2018, invading plants and aboveground part of ramie were cut and amendment was added to improve the growth of ramie plants. Plants and soil associated to the

root system were sampled in May (5 samples), July (3 samples) and November 2016 (3 samples) at different locations of the planted terraces. Soil associated to roots was collected by shaking, air-dried and sieved at $2 \mathrm{~mm}$. All the plants were divided into roots, stems and leaves and washed with tap water using ultrasound bath then rinsed with deionized water.

Then they were dried at $60^{\circ} \mathrm{C}$ and ground. In November 2018 , the stems of several plants were sampled for the analysis of fibers. Some stems reached $2 \mathrm{~m}$ in height. The stems were cut and air-dried for several days.

S2- Distribution of trace elements in the soil and plant samples collected in 2016 (mean \pm standard deviation, $n=11$ )

\begin{tabular}{l|ccccccccc}
\hline & \multirow{2}{*}{$\mathrm{Ba}$} & \multirow{2}{*}{$\mathrm{Rb}$} & \multirow{2}{*}{$\mathrm{Sr}$} & \multirow{2}{*}{$\mathrm{n}$} & \multicolumn{4}{c}{ REEs (in mg kg ${ }^{-1}$ ) } \\
\cline { 7 - 11 } & & & & $\mathrm{La}$ & $\mathrm{Ce}$ & $\mathrm{Nd}$ & $\mathrm{Y}$ & Sum $^{1}$ \\
\hline Leaves & $249 \pm 128$ & $50 \pm 33$ & $59 \pm 24$ & $260 \pm 74$ & $17.2 \pm 6.1$ & $7.1 \pm 6.6$ & $8.7 \pm 3.8$ & $23 \pm 12$ & $57 \pm 36$ \\
\hline Stems & $155 \pm 157$ & $63 \pm 31$ & $16 \pm 4$ & $149 \pm 57$ & $10.7 \pm 6.6$ & $3.0 \pm 1.5$ & $4.1 \pm 1.8$ & $6.3 \pm 3.4$ & $24 \pm 17$ \\
\hline Roots & $82 \pm 56$ & $38 \pm 19$ & $11 \pm 3$ & $118 \pm 36$ & $19 \pm 15$ & $7.8 \pm 2.8$ & $10.1 \pm 7.3$ & $16 \pm 18$ & $66 \pm 52$ \\
\hline Soil & $584 \pm 111$ & $295 \pm 32$ & $34 \pm 4$ & $165 \pm 36$ & $131 \pm 59$ & $173 \pm 33$ & $81 \pm 33$ & $107 \pm 58$ & $592 \pm 197$ \\
\hline
\end{tabular}

${ }^{1}$ sum of the concentrations of the 14 lanthanides and Y 